\title{
Healthy Israel 2020: Israel's Blueprint for Health Promotion and Disease Prevention
}

\author{
Elliot Rosenberg, MD, MPH, ${ }^{1}$ \\ Itamar Grotto, $\mathrm{MD}, \mathrm{PhD}, \mathrm{MPH},{ }^{1}$ \\ Tunie Dweck, MD, MPH, ${ }^{1}$ \\ Tuvia Horev, DMD, PhD, MPH, ${ }^{1}$ \\ Miri Cohen, MA, ${ }^{1}$ \\ Boaz Lev, MD, MHA ${ }^{1}$
}

\begin{abstract}
Israel's health system evolved over the past century and achieved universal coverage in 1995. Health status indicators have improved dramatically over the past decades and are now generally excellent compared with those of OECD countries. The Healthy Israel 2020 (HI2020) initiative was launched by the Ministry of Health in 2005 with the goal of creating a preventive blueprint to improve the quality of life, increase overall longevity, and maximize health equity among Israelis. Twenty committees were charged with generating reports that addressed health determinants such as health behaviors, health states such as infectious disease, age-related health states, or infrastructural aspects such as preventive education and training. Reports presented the local and international epidemiologic data, generated objectives and year 2020 targets, and compiled evidence-based interventions to achieve them. Obstacles included uneven committee leadership, redefinition and expansion of focus areas, and the absence of formal prioritization methods, among others. Nevertheless, significant progress occurred, and by 2009, a variety of scientific products had been generated. These ranged from scientific reports to peer-reviewed publications and scientific conference presentations. The first three reports dealt with key lifestyle behaviors: obesity control, enhancing physical activity, and healthful nutrition. These then served as the foundation for a major spinoff of the initiative, the National Program for the Promotion of an Active and Healthy Lifestyle. HI2020 has been a key factor in the development of tobacco control legislation, alcohol control efforts, pediatric injury control, skin cancer prevention, and intervention programs to prevent chronic disease in the disabled. Implementation efforts are refined through workshops attended by key professionals and other stakeholders. Future challenges include the timely updating of the reports, enhancing
\end{abstract}

\footnotetext{
${ }^{1}$ Israeli Ministry of Health, Jerusalem, Israel.

Corresponding Author Contact Information: Elliot Rosenberg at eli.rosenberg@moh. health.gov.il; Israeli Ministry of Health, Jerusalem, Israel.
} 
dissemination of lay and scientific information via traditional and social media, enhanced prioritization and funding of the initiative, and adoption of a cost-effective policy implementation program.

Key Words: Health targeting, Israel, health promotion, disease prevention, implementation

Recommended Citation: Rosenberg E, Grotto I, Dweck T, Horev T, Cohen M, Lev B. Healthy Israel 2020: Israel's blueprint for health promotion and disease prevention. Public Health Reviews. 2014;35: epub ahead of print.

\section{INTRODUCTION}

\section{General Setting}

The modern State of Israel was founded in 1948 within the general area of the ancient biblical Land of Israel in the Middle East on the eastern shore of the Mediterranean Sea. It is a relatively small county, measuring only 470 kilometers (290 miles) from north to south and 135 kilometers (85 miles) at its widest point (Figure 1). ${ }^{1}$

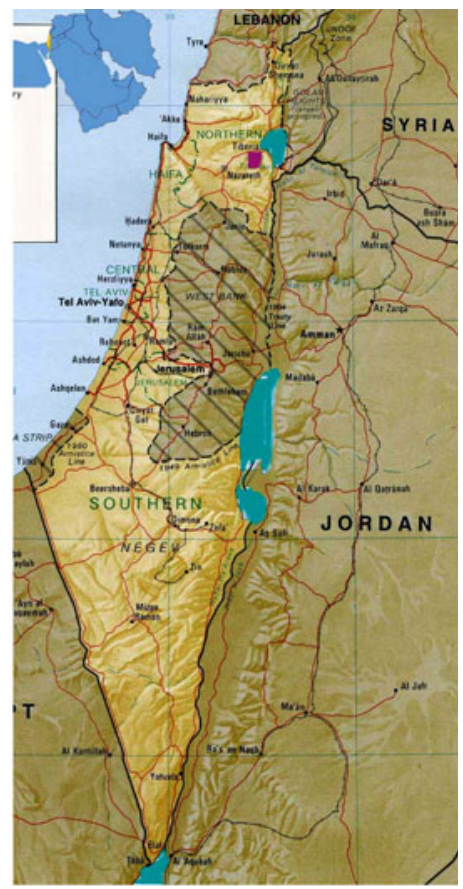

Fig. 1. Map of the Modern State of Israel. 
Since achieving nationhood, Israel experienced massive immigration from the Jewish Diaspora in other Middle-Eastern countries, post Holocaust Europe, and to some degree from the Americas, South Africa, and Australia. During the period from 1980-2005 there was a large influx of immigrants from two very different areas and cultures: nearly one million from the former Soviet Union, ${ }^{2}$ and roughly 80,000 from Ethiopia. ${ }^{3}$

This massive immigration, coupled with a high (3.0) average fertility rate for a developed country, ${ }^{4}$ have led to a near ten-fold increase in the population, growing from roughly 800,000 in 1948 to over eight million inhabitants in 2013..$^{5}$ Approximately 75 percent of the population is Jewish and 25 percent is of Arab or other ethnicity. The Jewish population is multiethnic, with 27 percent born outside of Israel. ${ }^{6}$ The Arab/non-Jewish population is primarily Moslem (82.5\%), with small Christian (9.5\%), and Druze (8\%) minorities. ${ }^{7}$

\section{Health Infrastructure}

Beginning in 1911, health care began to be provided by Sick Funds created by local labor unions. The Sick Funds were funded through membership fees. In 1973, a law was passed requiring employers to contribute as well. The 1995 National Insurance Law led to provision of government-financed universal health insurance for all Israeli citizens. The four health funds currently in operation are funded by the government on a per capita basis from payroll and general tax revenues. The employer health tax was cancelled in 1997. The National Insurance Institute, the organization responsible for social security in Israel, tranfers funding to the health funds through a capitation scheme that incorporates the number of insurees in each fund, their age, and other factors. These health funds competitively serve the citizenry, with the largest, Clalit, insuring roughly 50 percent of the population, the next largest fund, Maccabi, serving about 25 percent, and the other two (Meuhedet and Leumit) splitting the rest of the population between them. Close to half of the hospitals are owned and operated by the government, about a third by Clalit, and the rest are operated by a mix of for profit and not-for-profit organizations.

Health promotion and preventive care is delivered in a variety of ways: well-baby clinics ("Tipot Halav" or Drop of Milk stations, first established in 1922) are operated by both the government (national or municipal) and by the Clalit health fund. They provide health counseling, vaccines, child development services, and preventive examinations for pregnant women, infants, and children. District health offices are responsible for public health services such as infectious disease control, food hygiene, and traveler's health. 
Clinical therapeutic care and preventive medicine for the population is provided by a county-wide network of primary care physicians and nurses employed in community clinics by the four health funds. District health promoters provide support for a variety of health promotion initiatives along with local authorities and/or non-governmental organizations. Ambulatory patient data systems are world class, with full electronic medical file coverage for primary and specialist care. Israel's Quality Indicators in Community Healthcare program, along with health fund-based quality initiatives, have led to impressive gains in screening test coverage of the population over the past decade, e.g., fecal occult blood to detect colorectal cancer. Health promotion and preventive medical guidelines have been published by the Israeli Preventive Services Task Force since 1996 and have been updated on a regular basis since then, with the latest edition issued in early $2013 .^{8}$

New health technologies are reviewed annually by a multi-specialty "Health-Basket Committee" to advance public funding for new technologies, medications, and vaccines. A combination of evidence-based, ethical, and cost considerations are weighted to decide how best to spend the approximately US $\$ 100$ million dollar annual budget. Recent preventive additions to the basket have included tobacco cessation medication and group counseling, as well as the human papilloma virus vaccine. Vaccine coverage and inclusiveness in Israel is on par with most western countries with respect to pediatric vaccines. Influenza vaccines have recently been distributed free of charge by the various health funds. The herpes zoster vaccine for older adults still awaits public funding. ${ }^{9}$

\section{Health Outcomes}

Israeli citizens enjoy a long life expectancy. In 2011, life expectancy at birth was 81.8 years, nearly two years higher than the OECD average of 80.1 years. Israeli men, in particular, enjoy one of the highest life expectancies in the world. Infant mortality was 3.5/1000, below the OECD average of 4.1/1000.$^{10}$ A multi-year trend of life expectancy compared to European Region World Health Organization country groupings appears in Figure 2.

Based on a report from 2009, Israel ranked seventh and fifteenth (out of 34 OECD countries) in male and female coronary artery disease mortality, respectively. ${ }^{11(p .29)}$ Israel's preeminence is even more apparent with respect to stroke mortality: Israeli men have the lowest, and women the second lowest rate in the OECD. ${ }^{11(p .29)}$

These achievements in cardiovascular health may be traced to "upstream" preventive interventions, especially hypertension and hyperlipidemia detection and control. For example, over 90 percent of those aged 
55-74 measuring LDL cholesterol in the previous year had normal values ( $\leq$ $160 \mathrm{mg} / \mathrm{dl}$ ). Gradual annual improvement in adherence has been evident. ${ }^{12}$ Proactive hypertension and diabetes management is given high priority in primary care. ${ }^{13}$

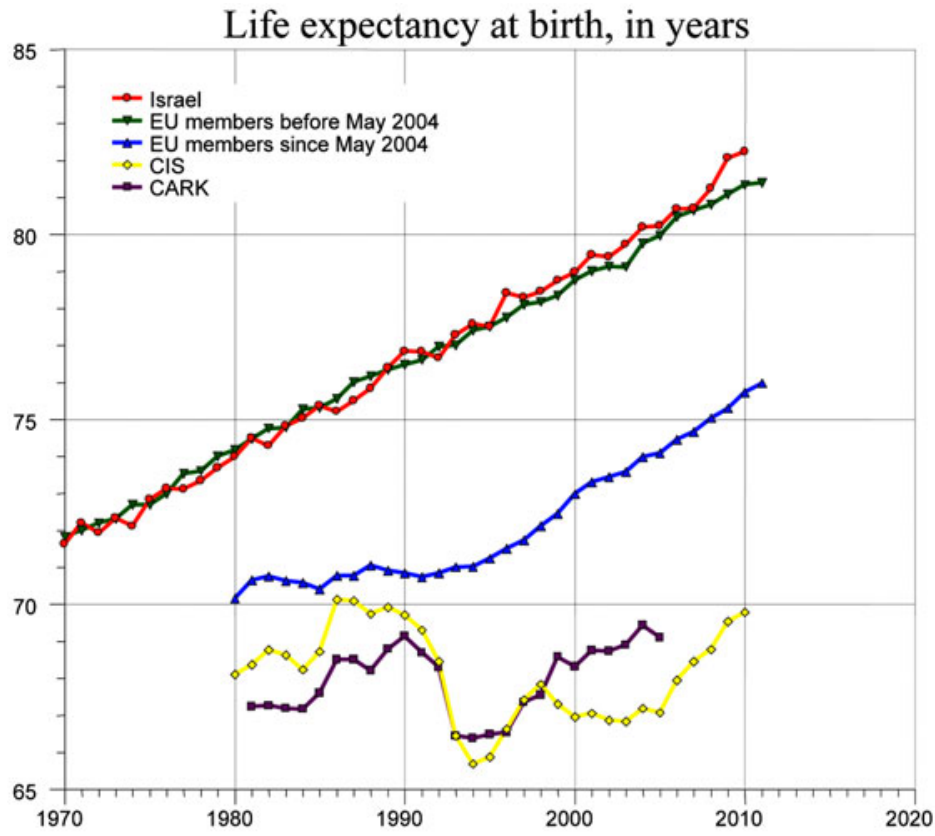

Fig. 2. Life Expectancy at Birth: Israel and WHO Regional Groupings of Countries 1970-2010.

EU = European Union; CIS = Commonwealth of Independent States; CARK = Central Asian Republics and Kazakhstan.

Source: World Health Organization Regional Office for Europe. European Health for All Data Base (HFA-DB). Updated July 2013. ${ }^{36}$

Despite these achievements on a national level, more work is needed to narrow gaps between disadvantaged groups in the population. Diabetes is a good example: prevalence is almost double in the Arab population relative to the Jewish population. ${ }^{12}$ There are also areas such as the incidence of cancer, for which the Arab population has traditionally experienced lower rates than the Jewish population. This gap, though, is shrinking in size, due to improved cancer screening and increased early detection in the Arab population, as well as the impact of unhealthful lifestyle behavior changes. ${ }^{14}$ 
Lifestyle behaviors present a mixed picture. Smoking prevalence has decreased in recent years and is below the OECD average of 22.3 percent. ${ }^{15}$ Yet prevalence in some populations is still quite high (e.g., 43.8\% of Arab males smoke). ${ }^{16}$ Forty-nine percent of Israelis are either overweight or obese. ${ }^{17}$ This is slightly (53\%) higher among the Arab population. Only 32 percent of adults age 21 and above are as physically active as recommended. ${ }^{18}$ Twenty percent sleep less than six hours nightly and 18 percent feel very sleepy during the day. Almost a quarter of the population is frequently stressed, and nine percent frequently feel depressed. ${ }^{19}$

The transport accident mortality rate declined from 12/100,000 to 5/100,000 from 1995 to 2010, and at 5.9 percent in 2011 was well below the OECD average of 7.6 percent. ${ }^{11(\mathrm{p} .33), 20}$ While improved post-crash care is partly responsible for these improved rates, it may also be explained by a reduction in the number of serious and fatal accidents.

Administration and adherence to certain preventive interventions is impressive: in 2011, vaccination rates of children ranged from 93 percent (Hib3) to 99 percent (HepB). ${ }^{21}$ On the other hand, among those 65 and above, only 57 percent received the annual vaccination against influenza. Only partial success has been achieved in improving adherence to cancer screening: in 2010, 68 percent of eligible women were screened for breast cancer with mammography. Colon cancer screening was even less widespread: only 47 percent of those eligible were screened. That said, a consistent improvement in coverage rates over time is evident. ${ }^{12}$

These data highlight various challenges facing the health system, but also demonstrate advances that have been made over recent years. But back in 2005, when senior leaders in the Ministry of Health (MOH) surveyed the preventive health landscape, the picture was not as encouraging as it is today. It was then that a decision was made to embark on a visionary initiative to be fully implemented 15 years in the future. The stage was set for the introduction of the Healthy Israel 2020 Initiative.

\section{THE HEALTHY ISRAEL 2020 INITIATIVE}

\section{Preparation and Launch}

The Healthy Israel 2020 (HI2020) initiative was conceived with a goal of creating a preventive blueprint to improve the quality of life, increase overall longevity, and maximize health equity among Israelis. This built upon an existing ethos of health promotion and prevention manifest in well-developed local programs such as Israel's well-baby clinics and 
community-oriented primary care system. ${ }^{22}$ On the other hand, the focus and funding streams of the health system revolved around treatment rather than prevention, as evident from the fact that Israel spent only 0.6 percent of its total health expenditure on prevention and public health services in 2005.

The concept of a prevention-oriented health-targeting initiative had already been established internationally. Utilizing the core concept of management by objective, ${ }^{23}$ the United States Healthy People initiative began defining health objectives with accompanying targets to reach over a decade, back in 1979. ${ }^{24}$ The WHO employed this methodology in its Health for All program, originally launched in 1979 as the Global Strategy for health for all in the year 2000 by the World Health Assembly. This document invited Member States to act individually in formulating national strategies and collectively in formulating regional and global strategies. ${ }^{25}$ Israel followed this model and drafted health objectives in 1989, but these were not formally implemented or funded by the $\mathrm{MOH}$. Consequently, they were only realized if they happened to coincide with preexisting organizational goals and objectives.

In contrast with its predecessor health targeting initiatives, HI2020 did not only formulate objectives and measurable targets: the scientific literature was carefully reviewed in order to formulate recommendations to be made based on proven strategies and evidence-based interventions to employ to meet the targets. Other criteria considered when deciding upon recommendations were their feasibility (in terms of political will, funding availability, and manageability) and public support. Where baseline data did not exist or there were insufficient data regarding the existence of interventions or their suitability to Israel, developmental data objectives and interventional objectives were set, respectively.

Thus in 2005, the Associate Director General of the Ministry of Health (Boaz Lev), a strong proponent of healthful lifestyle behaviors, led the decision to create the HI2020 initiative as a means of generating a preventive blueprint for Israel. Two professional staff members were hired to move the initiative forward: a national coordinator trained in epidemiology and biostatistics, and the lead author (Elliot Rosenberg), a specialist in general preventive medicine, to serve as scientific consultant to the initiative. A scientific committee, chaired by the Associate Director General of the Ministry of Health, was established. In addition to the aforementioned staff members, this committee included a senior $\mathrm{MOH}$ staff member with a health economic background as well as a seasoned staff member with 
experience in health promotion and legislation (Miri Cohen).* A steering committee composed of leaders in the health field from both government and nongovernmental organizations was formed oversee the entire process.

To implement the initiative, 20 committees were initially formed. The focus areas selected generally paralleled those of an existing similar initiative (US Healthy People 2010), with local adjustments. These included the focus areas in Box 1 (in bold) and their subdivisions, where relevant.

Committee composition was determined by the initiative's scientific committee. Each committee was led by either a health professional in a senior leadership position in the $\mathrm{MOH}$ or by a leading subject matter expert in each respective area. Committee members were selected from a variety of sources: government ministries, health funds, academic centers, and nongovernmental organizations. Subcommittees were created within committees as mandated by the scope and variety of the subject matter. For example, the health behaviors committee initially included six separate subcommittees to cover the topics of tobacco control, obesity control, nutrition, physical activity, sleep/alertness, and ultraviolet exposure/melanoma prevention. An international board of consultants from a variety of countries was recruited to assist each committee. All told, over 300 committee members and roughly 50 consultants were recruited.

Each committee/subcommittee received guidelines specifying the desired structure of the reports. These included the following: epidemiology/ disease burden, financial burden, objectives and target values (international and Israeli), recommended interventions, and references. Objectives were separately crafted by age, gender, and, where the data indicated the existence of a substantive gap between groups (e.g., BMI or physical activity level), by ethnic group (Jews and Arabs). Target values for the year 2020 were set in accordance with the baseline data and by assuming reasonable interventiondriven improvements over time. Several methods were used: achieving a better outcome than the leading subgroup for which data existed ("better than the best"), improving by a fixed percentage (e.g., 10\%), or continuing existing trends into the future. Finally, committees were charged with creating viable implementation plans for their recommendations: to prioritize the interventions on the basis of their scientific validity, their ability to reduce

\footnotetext{
* Over the 2007-2010 period personnel changes occurred in the management of the initiative and in the scientific committee: Elliot Rosenberg replaced the national coordinator of the initiative, a preventive medicine specialist (Tunie Dweck), took over as scientific consultant/ intervention specialist, and Itamar Grotto (a public health physician) and Tuvia Horev (a dentist with health economic training) joined the scientific committee, the latter replacing the original health economist who left the $\mathrm{MOH}$.
} 


\section{Box 1}

Healthy Israel 2020 Initiative Committees and Subdivisions

I Health State or Determinant

1. Health behaviors

1.1 Enhancing physical activity

1.2 Obesity control

1.3 Healthful Nutrition

1.4 Tobacco control

1.5 Prevention of excessive consumption of alcohol

1.6 Enhancing alertness

1.7 Prevention of eating disorders

1.8 Prevention of excessive ultraviolet radiation exposure

2. Equity

3. Environmental/Occupational health

4. Patient safety/quality of care

5. Infectious/Vaccine-preventable diseases

5.1 Prevention of vaccine-preventable diseases

5.2 Prevention of tuberculosis and AIDS

5.3 Prevention of sexually transmissible diseases

5.4 Prevention of zoonotic diseases

5.5 Prevention of infectious diseases through enhanced hygiene

6. Chronic disease prevention

7. Mental health

8. Oral health

9. Accident/Violence prevention

9.1 Prevention of pediatric injury

9.2 Prevention of school injury

9.3 Prevention of leisure injury

9.4 Prevention of violence

10. Prevention of chronic disease in the disabled

II Age-related

1. Maternal \& child health

1.1 Prevention of anemia in pregnancy and in newborns

1.2 Prevention of developmental disorders

1.3 Enhancing breastfeeding

2. Youth \& Adolescent health

3. Senior Health

III Infrastructural development/Utilitarian

1. Public health infrastructure

2. Human Resources, Education and Training

3. Cultivating partnerships outside the health sector

4. Data

5. Funding

6. Legislation/Enforcement

7. Health communications/Marketing 
the burden of disease, their cost-effectiveness, and their ability to reduce existing disparities between subpopulations, and to spell out, in general terms, how they envisioned their programs unfolding over time.

To direct committee heads, a conference was held in late 2005. A kickoff meeting for all committee members was attended by the Minister of Health and included international invited participants from the US Healthy People 2010 effort.

\section{Phase I: Writing the Reports}

Beginning in 2006, the committees began developing their reports. Each committee worked at its own pace, assisted as required by the HI2020 scientific committee. Over time, several challenges became apparent:

1. Leadership Commitment: Several committee chairs proved to be too busy to effectively move their committees forward. Others lacked sufficient grounding in delineating public health policy according to the requested format and scientific evidentiary criteria. Hence they were replaced by more appropriate chairs. Other chairs left their professional positions and were therefore replaced by those who took over for them, or they had co-chairs appointed to assist them. This naturally slowed the progress of those committees.

2. Data Availability: The initiative introduced the need for new, internationally benchmarked data. Existing data in some areas (e.g., aerobic physical activity) were determined to be inadequate due to the establishment of new scientific criteria. This led national survey centers such as the Israel Center for Disease Control and the Central Bureau of Statistics to add questions and topics to existing surveys, as well as find ways to continue existing data collection so as to allow trends to be followed over time.

3. Funding: As the HI2020 initiative was getting under way, a lump sum was allocated to cover the budgetary needs over the coming several years. This funded half a full time equivalent staff position (FTE), as well as limited consulting time for the committees, annual conferences and publications. On the other hand, the initiative did not become formally established as a department in the $\mathrm{MOH}$, and as such, did not receive secure annual funding or benefit from staff increases. This precluded hiring professionals to oversee the work of individual committees.

4. Changes in Focus Areas: As the committee work progressed, it became evident that the initial choice of topics, as well as the internal division between committees, needed revision. For example, the health behavior subcommittee on obesity recommended that a separate subcommittee be 
developed to cover the topic of eating disorders, and this was indeed approved. An awareness of increased alcohol intoxication, especially among youth, led to the establishment of a separate health behaviors subcommittee focused on the prevention of excessive alcohol consumption. The environmental and occupational health committee was initially empowered to cover both areas. As the scope of the topics became better understood, separation of the two areas into two committees was deemed necessary. Conversely, some committees and subcommittees either merged or were terminated. The maternal-child health and adolescent health areas were merged when it became clear that some of the planned subcommittee activity in the maternal-child focus area (viz., the prevention of prematurity and the prevention of intrauterine infections) would not be dealt with in the current phase of the initiative. The fact that one $\mathrm{MOH}$ department was responsible for both committees facilitated this decision. The mandate of other committees was rescinded due to a variety of professional and organizational considerations. An example of the former was the creation of separate multi-organizational committees outside of HI2020 to deal with patient safety, medical quality, and the restructuring of the public health infrastructure. An example of the latter included the determination that inter-ministerial coordination, legislation, and funding could be handled by existing $\mathrm{MOH}$ departments.

As larger committees proved difficult to move forward, it was concluded that in the future, committees consisting of roughly five members, aided by an evidence-based policy research assistant and a trained scientific writer, and which consulted non-committee member subject matter experts as needed, would be optimal.

Annual conferences were held for committee heads in 2006 and 2007 in order to present work in progress and to discuss open issues. In April 2009 the initiative hosted Dr. Jonathan Fielding, the head of the US Healthy People 2020 initiative, at a conference celebrating the completion of committee work by a majority of committees and subcommittees.

Over the 2006-2009 period, numerous presentations about the initiative were given at national scientific meetings both in Israel and in the US, at meetings of the National Councils of Health, and to students in schools of public health. In addition, both lay and peer-reviewed articles ${ }^{26}$ were written and electronic media with chapter highlights were disseminated. 


\section{Phase II: Implementation}

\section{Direct Spinoffs}

The highest profile and most productive committee in the Healthy Israel initiative has always been the health behaviors committee. Several possible explanations for this phenomenon exist: the clear perception that the topics covered by this committee were key preventive/upstream determinants of health; the fact that the committee chair, as well as its subcommittee chairs are prominent leaders in the both the $\mathrm{MOH}$ and in the field of health promotion and disease prevention in Israel; and the existence of strong public and private support for prevention. ${ }^{27}$ Thus, it is not surprising that the first reports to be published were those dealing with enhancing physical activity, obesity control, and healthful nutrition.

To capitalize on these advantages, the $\mathrm{MOH}$ embarked on an ambitious implementation program in this area beginning in 2008. Two other relevant ministries were brought in as partners: the Ministry of Education and the Ministry of Culture and Sports. By the time the current Director General (DG) of the $\mathrm{MOH}$ entered the Ministry in 2010, preparations for national implementation were in place. The enthusiasm and drive of the DG, the Associate DG, the Head of Public Health Services, and the staff of the department of Health Promotion and Education in the $\mathrm{MOH}$, helped in developing a multifaceted implementation effort entitled the National Program for the Promotion of an Active and Healthy Lifestyle. This includes legislative, educational, clinical, and interventional programs in schools, workplaces, primary care clinics, and in the community at large. ${ }^{28}$ A major achievement was the Israeli government decision rendered in late 2011 to support and fund the various interventional components over the 2012-2015 period.

An additional important achievement stemming from the HI2020 initiative was the development of a broad-sweeping legislative agenda in the area of tobacco control. This may be attributed to the prominence of tobacco use among the preventable causes of death ${ }^{29}$ and the perception among the top echelon $\mathrm{MOH}$ leadership that public and parliamentary support was strong. This effort led to the passing of an ambitious suite of tobacco control legislation. Details may be found in recent publications whose first author, Laura (Leah) Rosen, was the head of the HI2020 committee on tobacco control (and the first national coordinator of the HI2020 initiative). ${ }^{30,31}$

Another creative program developed on the basis of the work of a HI2020 committee report (Preventing chronic disease in the disabled) is the "Stepping Stone" health promotion and safety enhancement program for 
the disabled currently fielded by the Myers-JDC-Brookdale Institute in Israel. This collaboration developed as a result of the fortuitous dovetailing of the completion of the HI2020 report and the interest of the Myers-JDCBrookdale Institute in evidence-based health promotion and safety for their mandated programs.

More recently, the intervention section of the pediatric injury prevention committee was updated and utilized by the National Program for the Prevention of Pediatric Injury and the entire prevention of excess ultraviolet radiation exposure was updated and sent to the State Comptroller to assist in the development of that office's report on skin cancer prevention. These contributions are evidence of the esteem with which HI2020 reports are held due to their evidence-based utility in the eyes of senior government decision-makers.

\section{Implementation Workshops}

In order to develop detailed implementation plans from the HI2020 reports, the scientific committee decided to develop a series of topical one-day workshops. These have included committee members from the scientific committee, as well as from the committee or subcommittee whose work was being discussed. Also invited were health and other professionals (e.g., health communication experts, health economists, legal experts) and key decision-makers thought to be instrumental in carrying the recommendations to fruition. Additionally, leading members of health related nongovernmental organizations such as "Or-Yarok" ("Green Light" in Hebrew), which advances the cause of traffic safety in Israel, have attended. Thus far, workshops have been held on a variety of topics such as geriatric health, sleepiness prevention/alertness enhancement, preventing excessive intake of alcohol, and oral health.

\section{CURRENT AND FUTURE CHALLENGES}

HI2020 has established itself as a key feature in the Israeli health landscape, bringing health promotion and disease prevention into sharper focus than ever before. This has been achieved through its publications, internet site offerings, conferences, and incorporation into the curriculum of university health promotion degree courses and medical residency syllabi. Its sciencebased, cutting edge content has been recognized by a series of international bodies: the alcohol control report was presented to the French National Academy of Medicine and was received "with honor." ${ }^{32}$ In November 2011, the First WHO European Conference on the New European Policy for Health 
- Health 2020 was held in Jerusalem, in part, to recognize Israel's leadership in the area of health targeting for 2020. Needless to say, the initiative has broad cachet among health professionals and decision-makers in Israel.

Yet, significant challenges remain.

Reports have been completed in a staggered fashion over the previous years. Some have required extensive and time-consuming editing. This has proved challenging, given the multiple other responsibilities of the $\mathrm{MOH}$ staff tasked to complete them. Thus, publication of the reports has been delayed. This in turn, has required the updating of the epidemiologic data, the objectives, and even more importantly, the legislative proposals and the science-based strategies and interventions in each report. A welcome recent development has been the authorization of additional staff.

While tracking progress towards the ultimate targets of the various objectives, it became clear that the system of setting the target values as "better than the best", assuming a continuation of existing trends into the future, and even fixed "stretch goals" was overambitious. Consequently, most target values have been modified in a similar fashion to the US Healthy People 2020, such that they are typically a ten percent change over the decade.

HI2020 has not only tried to keep current scientifically, it has also worked to utilize cutting edge technology to disseminate its findings. This led to an extensive overhaul of its original relatively basic internet site and to the development of plans for communication and marketing via other social media and to the incorporation of advanced features such as personal health calculators and other interactive elements, as well as fora with various online communities. This has been compounded by a general revamping of the $\mathrm{MOH}$ internet site, and the need to coordinate efforts with a broad array of other professionals. Hence, the launch of the initiative's new website was delayed until 2013.

When HI2020 was conceived, it was envisioned that a systematic prioritization process would be employed to direct the generation of reports, implementation activities, and the funding of projects. Proposals were submitted to facilitate this goal, but, unfortunately, did not prove practicable. Instead, real world drivers such as the perceived relevance to health and the perceived interest and receptivity by the public and various professional groups and decision-makers have thus far determined prioritization. A typical example of a high priority topic is tobacco control. As previously mentioned, an aggressive and successful legislative effort was launched to advance this cause. This has inevitably led to slower implementation of other, lower priority interventions. The fortification of basic foods such as flour with folic acid to prevent neural tube defects is one such example. 
Part of the challenge in developing a useful prioritization tool is in generating appropriate data about the cost-effectiveness of the interventions and the degree to which they reduce disparities. Some work in this has been done by $\mathrm{MOH}$ staff, ${ }^{33}$ but much more remains to be done. Multi-dimensional indices have recently been used to assist senior policymakers in prioritizing implementation recommendations in the focus area of Senior Health. ${ }^{34}$ It remains to be seen whether this proves to be a harbinger of more extensive prioritization efforts.

Despite the originality and innovativeness of the HI2020 it has not operated in a vacuum. Both within the $\mathrm{MOH}$ and most certainly outside it, new preventive initiatives have been developed and launched over the past five years or so. Some examples include a national program for alcohol control developed several years ago by the Israel Anti-Drug Authority and driver fatigue prevention programs developed by the Ministry of Transportation and the National Road Safety Authority. Comprehensive horizon scanning and enhanced inter-organizational cooperation will be needed to assure appropriate integration between programs.

Even when all the reports have been completed and posted on the new $\mathrm{MOH}$ website or published, the following questions will remain: how frequently should these reports be updated and by whom? This is complicated by the fact that the committees and subcommittees that developed the reports were volunteer groups which disbanded years ago. A related question revolves around the topic of implementation workshops currently run by the HI2020 scientific committee. Will these prove an effective mechanism to advance the ultimate implementation? Should scarce HI2020 staff time be spent organizing and running an ever growing number of such workshops? These and related questions will need to be resolved by senior $\mathrm{MOH}$ leaders over the coming years.

Relevant epidemiologic data have become more readily available over the past decade, due to closer cooperation between data generating organizations within Israel. However, lacunae still exist due to issues such as divergent definitions of key variables, proprietary software which prevent linkage of data systems, patient privacy concerns, and others. Closing these gaps will require such innovative projects as the European Union Twinning Project, ${ }^{35}$ which has was launched in 2013, pairing the Israeli Central Bureau of Statistics with Statistics Denmark, in an effort to improve the quality and international comparability of Israel's data in key policy-relevant domains.

Funding the interventions is a formidable challenge. Thus far, the $\mathrm{MOH}$ has succeeded in securing initial funding of the interventions to be fielded by the National Program for the Promotion of an Active and Healthy Lifestyle. Other programs have been funded in part by research grants. 
Implementing the extensive number of HI2020 committee interventions in a timely and effective manner will require detailed multi-year planning that incorporates equitable and scientifically-derived prioritization, as well as innovative financing schemes such as those utilizing joint public and private funding. At this time, a new proposal to provide stable annual funding for the initiative is being considered by senior $\mathrm{MOH}$ decision-makers.

Will the year 2020 see the HI2020 initiative reach its goals? Will Israel then embark on an even more ambitious program for 2030 or beyond? Although the biblical prophets are long gone from Israel, with 2020 vision we may be right on target.

Acronyms List:

HI2020 $=$ Healthy Israel 2020

$\mathrm{MOH}=$ Ministry of Health

Conflicts of Interest: None declared.

\section{REFERENCES}

1. Israel Ministry of Foreign Affairs. Israel in Brief. Available from URL: http:// www.mfa.gov.il/mfa/facts\%20about\%20israel/israel\%20in\%20brief/ (Accessed 25 March 2014).

2. Jewish Virtual Library. Immigration to Israel: total immigration, from former Soviet Union 1948-present. Available from URL: http://www.jewishvirtual library.org/jsource/Immigration/FSU.html (Accessed 31 March 2013).

3. Israel Central Bureau of Statistics. Table 1. Immigrants of Ethiopia, by period of immigration, sex, and age at time of immigration. 2010. Available from URL: http://www.cbs.gov.il/www/population/805/2010/t01.pdf (Accessed 25 March 2014).

4. Israel Central Bureau of Statistics. Statistical Abstract of Israel 2012. No. 63. Subject 3. Table 3.13. Fertility rates by age and religion. Available from URL: https://archive.is/o/PyCPV/http://www.cbs.gov.il/shnaton63/st03_13.pdf (Accessed 25 March 2014).

5. Israel Central Bureau of Statistics. February 2014 update. Table B/1. Population by population group. Available from URL: http://www1.cbs.gov.il/publications 14/yarhon0214/pdf/b1.pdf (Accessed 13 March 2014).

6. Israel Central Bureau of Statistics. Statistical Abstract of Israel 2012. No. 63. Subject 2. Table 2.24. Jews, by country of origin and age. Available from URL: http://www1.cbs.gov.i1/reader/shnaton/templ_shnaton_e.html?num_tab=st02 _24x\&CYear=2012. (Accessed 25 March 2014).

7. Israel Central Bureau of Statistics. Statistical Abstract of Israel 2012. No. 63. Subject 2. Table 2.19. Population, by population group, religion, sex, and age. Available from URL: http://www1.cbs.gov.il/reader/shnaton/templ_shnaton_e. html?num_tab=st02_19\&CYear=2012 (Accessed 30 March 2013). 
8. Israeli Medical Association, Israeli Association of Family Physicians. Clinical Guidelines. Recommendations of the Israeli Task Force on Health Promotion and Disease Prevention. Tabenkin H, Lahad A, (editors). Ramat-Gan, Israel: Israeli Medical Association and Israeli Association of Family Physicians; 2013.

9. Rasooly I. Personal communication. March 2014.

10. OECD Health Statistics 2013. Frequently requested data. OECD; 2013. Available from URL: http://www.oecd.org/els/health-systems/OECD-HealthStatistics-2013-Frequently-Requested-Data.xls\#'Frequently Requested Data' !A1 (Accessed 11 March 2014).

11. OECD. Health at a Glance 2011: OECD Indicators. OECD Publishing; 2011. Available from URL: http://dx.doi.org/10.1787/health_glance-2011-en (Accessed 2 April 2014).

12. National Program for Quality Indicators in Community Healthcare. 2008-2010 Quality Indicators for Community Health program. Available from URL: http://www.health.gov.il/Publicationsfiles/qindicatorsReport2008-2010.pdf (Accessed 25 March 2014). [In Hebrew]

13. OECD. OECD Reviews of Health Care Quality: Israel 2012: Raising Standards. OECD Publishing; 2012. Available from URL: http://www.oecd-ilibrary.org/ fr/social-issues-migration-health/oecd-reviews-of-health-care-quality-israel2012_9789264029941-en (Accessed 25 March 2014).

14. Israel Ministry of Health. Health in Israel: Selected Data 2010. Jerusalem: MOH; 2010.

15. OECD. OECD Factbook 2011-2012: Economic, Environmental and Social Statistics. OECD Publishing; 2011. Available from URL: http://www.oecdilibrary.org/economics/oecd-factbook-2011-2012_factbook-2011-en (Accessed 25 March 2014).

16. Israel Ministry of Health. Health Minister's Report on Smoking-2011. MOH; 2012.

17. Israel Central Bureau of Statistics. Social Survey 2010. Central Bureau of Statistics; 2011.

18. Israel Ministry of Culture and Sports, Israel Ministry of Health. Physical activity survey among Israelis age 21 and above. Ministry of Culture and Sports, Ministry of Health; 2012.

19. Israel Central Bureau of Statistics. Selected data from the 2010 Social Survey on Health and Way of Life. Central Bureau of Statistics; 2011. Available from URL: http://www.cbs.gov.il/reader/newhodaot/hodaa_template.html?hodaa= 201119238 (Accessed 2, 2013).

20. OECD. Health at a Glance 2013: OECD Indicators. OECD Publishing; 2013. Available from URL: www.oecd.org/els/health-systems/Health-at-a-Glance2013.pdf (Accessed 25 March 2014).

21. World Health Organization. Israel: WHO and UNICEF estimates of immunization coverage: 2011 revision. Available from URL: http://www. who.int/immunization_monitoring/data/isr.pdf (Accessed 31 March 2013). 
22. Epstein L, Gofin J, Gofin R, Neumark Y. The Jerusalem experience: three decades of service, research, and training in community-oriented primary care. Am J Public Health. 2002;92:1717-21.

23. Drucker PF. The Practice of Management. New York (NY): HarperCollins Publishers, Inc; 1954.

24. HealthyPeople.gov. History and development of Healthy People. U.S. Department of Health and Human Services; last updated 15 November 2011. Available from URL: http://www.healthypeople.gov/2020/about/history.aspx (Accessed 25 March 2014).

25. World Health Organization. Global Strategy for Health for All by the Year 2000. Geneva: WHO; 1981. Available from URL: http://whqlibdoc.who.int/ publications/9241800038.pdf (Accessed 11 March 2014).

26. Rosenberg E, Lev B, Bin-Nun G, McKee M, Rosen L Healthy Israel 2020: a visionary national health targeting initiative. Public Health. 2008;122:1217-25.

27. Kaplan G, Baron-Epel O. The public's priorities in health services. Health Expect. 2013 Apr 3: epub ahead of print.

28. Kranzler Y, Davidovitch N, Fleischman Y, Grotto I, Moran D, Weinstein R. A health in all policies approach to promote active, healthy lifestyle in Israel. Isr J Health Policy Res. 2013;2:16.

29. US Burden of Disease Collaborators. The state of US health, 1990-2010: burden of diseases, injuries, and risk factors. JAMA. 2013;310:591-608.

30. Rosen LJ, Geva H, Connolly G. Political will ushers in a new era for tobacco control in Israel. Lancet. 2011;378:1697-8.

31. Rosen LJ, Rier DA, Schwartz R, Oren A, Kopel A, et al. Public support for smoke-free areas in Israel: a case for action. Health Policy. 2012;106:161-8

32. Tulchinsky TH. Personal communication. 2012.

33. Ginsberg GM, Rosenberg E. Economic effects of interventions to reduce obesity in Israel. Isr J Health Policy Res. 2012;1:17.

34. Rosenberg E, et al. Development of a prioritization model to rank health objectives and interventions. Lessons learned from the senior health committee of Healthy Israel 2020. Presented at the 4th International Conference, Improving Health and Healthcare-Who is Responsible? Who is Accountable? Jerusalem, Israel: Israeli National Institute of Healthcare Policy; December 2009.

35. Delegation of the European Union to Israel. EU Twinning Project supports the development of the statistical system of Israel (27/05/2013). Available from URL: http://eeas.europa.eu/delegations/israel/press_corner/all_news/news/ 2013/20130527_en.htm (Accessed 28 November 2013).

36. World Health Organization Regional Office for Europe. European Health for All Data Base (HFA-DB). Updated July 2013. Available from URL: http:// www.euro.who.int/en/data-and-evidence/databases/european-health-for-alldatabase-hfa-db (Accessed 25 March 2014). 